Percepção das mães de pacientes sobre o atendimento odontológico infantil na Clínica Escola de odontologia da Universidade de Gurupi

Perception of the mothers of patients about child dental care at the Dental School of the University of Gurupi

Anne Fernandes Marques', Izabela Pereira Santos², Vinicius Lopes Marinho ${ }^{3}$

\section{RESUMO}

Neste estudo investigou-se a percepção das mães sobre o atendimento odontológico infantil na Clínica Escola de Odontologia da Universidade de Gurupi. Tratou-se de um estudo descritivo com abordagem qualitativa. A coleta de dados foi realizada por meio de entrevistas realizada com mães de pacientes da clínica de odontopediatria. Observou-se que, para as mães entrevistadas, o dentista ideal deveria ter afinidade com o paciente, formando então laços afetivos e é preciso haver relação interpessoal e fornecer informações não só sobre a assistência prestada, mas também sobre a qualidade do ensino que estes alunos obtêm, portanto, esta pesquisa possibilitou conhecer a percepção deste grupo de mães e revelou que elas encontram-se satisfeitas com o tratamento oferecido.

Palavras-chave: Atendimento infantil, percepção, mães.

\section{ABSTRACT}

In this study we investigated the mothers' perception of children's dental care at the Clinical Escola de Odontology, Universidad de Gurupi. It was a descriptive study with a qualitative approach. Data collection was carried out through interviews with mothers of patients at the pediatric dentistry clinic. It was observed that, for the interviewed mothers, the ideal dentist should have an affinity with the patient, thus forming affective bonds and it is necessary to have an interpersonal relationship and provide information not only on the care provided, but also on the quality of teaching these students therefore, this research made it possible to know the perception of this group of mothers and revealed that they are satisfied with the treatment offered.
Acadêmica do curso de Odontologia. Universidade de Gurupi.

Acadêmica do curso de Odontologia. Universidade de Gurupi.

3 Psicólogo. Doutorando em Ensino pela Universidade do Vale do Taquari, Mestre em Ciências da Saúde pela Universidade Federal do Tocantins/UF.

Endereço para correspondência: Vinicius Lopes Marinho Universidade de Gurupi/Unirg, Av. Rio de Janeiro $n \div 1585$, Centro -77403-090, Gurupi -TO, Telefone: (63) 3612-760

Keywords: Child care, perception, mothers.

\title{
1. INTRODUÇĀO
}

O tratamento odontológico é necessário para todos, independente do grau de escolaridade, classe social ou faixa etária. Cuidar da saúde bucal para muitos, apesar do desenvolvimento tecnológico frequente na Odontologia, envolve medo e tensão perante o cirurgião dentista. Na odontologia, as palavras como medo e/ou ansiedade são palavras usadas com frequência como obstante pelos pacientes, estão associados a inúmeros fatores etiológicos como, por exemplo: experiências odontológicas traumáticas, não 
conhecimento do cirurgião dentista, os aspectos psicológicos e possibilidade da dor. No paciente infantil, com a falta de entendimento e maturidade esse medo e ansiedade se manifestam de formas diferentes, como irritabilidade, taquicardia, tontura, choro, tremores, diarreia e principalmente a não aceitação do tratamento. ${ }^{1}$

O comportamento infantil apresenta grande impacto no consultório odontológico, buscando assim caracterizar como primeiro passo uma relação satisfatória entre a criança, o responsável e o profissional. Nesse sentido, o apoio familiar pode ter grande importância no conhecimento dos fatores psicossociais evitando para a criança uma imagem negativa da assistência odontológica, considerando que a satisfação dos pais é um fator preponderante na promoção da saúde infantil, uma vez que eles são os mediadores entre o profissional da saúde e a criança, não só por acompanharem as consultas, mas também por realizarem comunicação íntima com os filhos pois são os principais responsáveis pela aplicação das recomendações e dos tratamentos que os profissionais indicam. $^{2}$

Dessa forma, as informações dadas pelas mães auxiliam para a criação de uma base com a finalidade de que haja entendimento sobre os impactos psicossociais da intervenção dos dentistas pediátricos, pois durante a infância envolvem maneiras que somente por meio de um responsável são viáveis interferir. Assim, as mães dos pacientes devem estar satisfeitas e informadas sobre as ações relativas ao tratamento para que haja efetividade dos procedimentos realizados, visto que a satisfação dos pais com o atendimento influenciará a saúde de seus filhos. ${ }^{2}$

É evidente a escassez de estudos que investiguem a percepção das mães diante de atendimentos odontológicos, sendo um importante meio para compreensão do olhar e sentimentos maternos diante de tal situação. Estudos como esses contribuem para a construção de conhecimento sobre esse fenômeno na literatura e possibilitando a clínica a implantar/implementar novas estratégias de atendimento, levando em consideração os aspectos biopsicossocial das mães e das crianças atendidas tornando assim 0 atendimento odontopediátrico o mais confortável possível para as mães e possibilitando uma melhor abordagem tanto pela Universidade quanto para os acadêmicos.

Diante do exposto a pesquisa teve como objetivo geral investigar a percepção das mães de pacientes sobre o atendimento odontológico infantil na Clínica escola de Odontologia da Universidade de Gurupi. 


\section{MATERIAIS E MÉTODOS}

Tratou-se de uma pesquisa de aspecto exploratório, do tipo descritivo com abordagem qualitativa. $O$ estudo foi realizado com as mães de pacientes da clínica de odontopediatria na Universidade de Gurupi, situada na Avenida Pará, número 1544, centro Gurupi. Adotaram-se os seguintes critérios de inclusão: ser mãe de paciente infantil em atendimento na clínica escola de odontologia; ter realizado no mínimo 3 consultas; aceitar participar da pesquisa; estar ciente e assinar o Termo de Consentimento Livre e Esclarecido. Os de exclusão foram: não ter filho em atendimento na clínica escola de odontologia; ter realizado número inferior a 3 consultas; recusar a participação da pesquisa; não indicar ciência e assinar o Termo de Consentimento Livre e Esclarecido.

A pesquisa foi submetida ao Comitê de Ética em Pesquisa envolvendo Seres Humanos conforme o CAA 23626619.9.0000.5518 e aprovada conforme parecer oㅡ 3.653.942. O instrumento para a coleta de dados foi um roteiro de entrevista semiestruturada realizada com as mães em uma sala da Clínica Escola de Odontologia da Universidade de Gurupi. As mesmas tiveram os áudios gravados e posteriormente foram realizas as transcrições na íntegra. Os dados foram analisados por meio da análise de conteúdo de Bardin, chegando as seguintes categorias: I-Percepção da mãe sobre $o$ atendimento prestado; II- Pontos positivos e negativos do serviço prestado e III-O dentista ideal sob a ótica das mães.

\section{RESULTADOS E DISCUSSAOO}

Participaram do estudo 03 mães de crianças atendidas na Clínica escola de Odontologia da Universidade de Gurupi. A proposta inicial da pesquisa era realizar um estudo com 20 mães, no entanto devido ao contexto atual da pandemia da Covid-19 e consequentemente a suspensão das atividades da instituição como um todo, não houve possibilidade de coletar dados de outras participantes. Inicialmente será realizada uma caracterização dos participantes levando em consideração as seguintes variáveis: faixa etária, estado civil, nível de escolaridade e renda. 
DOI: 10.18606/2318-1419/amazonia.sci.health.v8n2p77-85
MARQUES AF. SANTOS IP. MARINHO VL.

Percepção das mães de pacientes sobre o atendimento odontológico infantil na Clínica Escola de Odontologia da Universidade de Gurupi.

Tabela 1 - Caracterização dos participantes da pesquisa.

\begin{tabular}{llc}
\hline VARIÁVEIS & N. & $\%$ \\
\hline FAIXA ETÁRIA & 2 & $66,6 \%$ \\
\hline 25 a 35 anos & & \\
\hline 36 a 45 anos & 1 & $33,3 \%$ \\
\hline Mais de 45 anos & & \\
\hline ESTADO CIVIL & - & - \\
\hline Solteira & 3 & $100 \%$ \\
\hline Casada & - & - \\
\hline União Estável & - & - \\
\hline Divorciada & - & - \\
\hline Viúva & & \\
\hline NíVEL DE ESCOLARIDADE & - & - \\
\hline Ensino Fundamental Incompleto & - & - \\
\hline Ensino Fundamental Completo & - & - \\
\hline Ensino Médio Incompleto & 3 & $100 \%$ \\
\hline Ensino Médio Completo & - & - \\
\hline Ensino Superior Incompleto & & \\
\hline RENDA & - & - \\
\hline 01 Salário mínimo & 2 & $66,6 \%$ \\
\hline Entre 02 e 03 salários mínimo & 1 & $33,3 \%$ \\
\hline Mais de 03 salários mínimos & & \\
\hline
\end{tabular}

Das 3 mães que participaram, duas estavam entre a faixa etária de 25 a 35 anos $(66,6 \%)$ e apenas uma tinha mais que 45 anos de idade $(33,3 \%)$, todas as mães eram casadas e possuíam ensino médio completo, 2 mães apresentaram entre 2 e 3 saláriosmínimos (66,6\%) somente uma mãe apresentou mais de 3 salários-mínimos (33,3\%).

Tabela 2- Número e idade dos filhos, início do tratamento na Clínica Escola de Odontologia-UNIRG, motivo da consulta inicial

\begin{tabular}{|c|c|c|c|}
\hline Entrevistada & $\begin{array}{l}\text { Número de } \\
\text { filhos }\end{array}$ & Idade dos Filhos & $\begin{array}{l}\text { Motivos da } 1^{\circ} \\
\text { Consulta }\end{array}$ \\
\hline Mãe 1 & 3 & $\begin{array}{c}\text { 14anos, } 8 \text { anos }^{*} \mathrm{e} \\
6 \text { anos }^{*}\end{array}$ & Carie dental. \\
\hline Mãe 2 & 10 & $\begin{array}{c}29 \text { anos, } 23 \text { anos, } \\
21 \text { anos, } 19 \text { anos, } \\
15 \text { anos, } 14 \text { anos, } \\
12 \text { anos, } 11 \text { anos, } \\
9 \text { anos }^{*} \text { e } 7 \\
\text { anos }^{*} .\end{array}$ & Carie dental. \\
\hline Mãe 3 & 3 & $\begin{array}{c}12 \text { anos, } 10 \text { anos* } \\
10 \text { anos }^{*}\end{array}$ & Carie dental. \\
\hline
\end{tabular}


Das 3 mães entrevistadas, uma têm dez filhos com idades entre 7 e 29 anos e as outras duas mães têm três filhos com idades entre 6 e 14 anos. Todas as entrevistadas alegaram que procurou atendimento odontológico na clínica da Universidade de Gurupi por motivo de dentes cariados em seus filhos. *Crianças em atendimento na clínica.

\subsection{PERCEPÇÃO DA MÃE SOBRE O ATENDIMENTO PRESTADO}

Analisando a concepção das mães sobre o atendimento odontopediátrico da clínica escola de odontologia da Universidade de Gurupi, as mesmas mostraram-se satisfeitas e valorizaram sobretudo o contato dos acadêmicos com as responsáveis e crianças em atendimento, enaltecendo o vínculo, assim como achado de Robles ${ }^{3}$ que as expectativas das entrevistadas giraram em torno de habilidades técnicas e afetivas.

A redução da ansiedade é essencial para o tratamento odontológico e para a motivação do paciente. Modificar conceitos negativos de experiências anteriores é muito importante. Com base nos relatos relacionado as reações das crianças no dia de retorno ao consultório, acreditamos que a forma e conduta seguida pelos acadêmicos é fundamental para as reações positivas delas ${ }^{4}$ assim como relata as mães: [...]Meu Deus, ficam contando as horas pra chegar logo" (M1). [...] Eles acham bom vir. (M2). [...] elas faltam me deixar doida. (M3).

O fato de o dentista saber conversar sobre outros assuntos, quebrando o gelo antes, durante e após a consulta desenvolvendo uma relação de amizade com o paciente é essencial ${ }^{3}$, assim como o relato da $M 1$, que diz sobre a afinidade do acadêmico com seu filho: [...] a minha filha gostou muito da moça que está tratando dela, ave-maria estão se falando direto no WhatsApp.

Há um consenso de que atitude ou expectativas do dentista podem afetar o resultado da consulta. É necessário conhecer o tipo de comportamento infantil e alguns aspectos do desenvolvimento para facilitar o relacionamento dentista e criança, portanto, é importante oferecer garantias de que a situação será menos ameaçadora possível, transmitindo segurança e cativando a criança através do vínculo afetivo, assim, a recompensa deve surgir como um brinde após a consulta. ${ }^{5}$ Quando questionadas sobre como os filhos recebiam o atendimento, as mães relatam: [...] Minha filha gosta muito da Doutora, cuida bem dela. (M1). [...] Eles gostam porque as meninas conversam com eles, 
dá balão (M2) [...] inclusive ela ganhou um presente da dentista, então isso foi o máximo. M3.

\subsection{PONTOS POSITIVOS E NEGATIVOS DO SERVIÇO PRESTADO}

Através do papel de orientador do cirurgião-dentista, deve ter em vista uma base do acolhimento na promoção de saúde aos pacientes, deixando características positivas e satisfeitas na percepção das mães sobre o atendimento prestado conforme relato das entrevistadas: [...] Não tenho nada do que reclamar pra mim à forma que atende está bom. (M1).

Uma das razões desse contentamento é a informação e orientação dada pelos acadêmicos para as mães sobre higiene bucal das crianças: [...]tratam a gente superbem, explica se tiver alguma dúvida, eles explicam como deve fazer pra cuidar dos dentinhos dos nossos filhos. (M1).

Para Rigo et al. $^{6}$ as mães desempenham um papel fundamental como transmissoras do bom hábito para a saúde bucal de seus filhos. Dessa forma, quanto mais vasto o conhecimento delas sobre atitudes positivas em relação a hábitos bucais, melhores serão as condições bucais das crianças.

É muito importante a capacitação dos alunos de Odontologia para o acolhimento da subjetividade dos pacientes, com vistas à obtenção de comportamentos mais colaborativos, com maior resolutividade no atendimento, assim, fatores interpessoais da relação acadêmico e paciente. ${ }^{7}$ Que foram mencionados pelas mães, tais como: [...] eu chego e as meninas já estão prontas para atender. (M3) [...] Eu vim aqui e já fui atendida, pegaram meu contato e já mandaram mensagem. (M2).

Alguns pontos como a falta de pontualidade no atendimento foram citados: [...] $O$ ruim é só porque é um pouquinho demorado, acho que devido à quantidade de alunos. (M1). [...] às vezes ocorre de chegarmos e esperar um pouquinho, mas isso é normal, eu não acho que seja um ponto negativo. (M3).

A compreensão do acolhimento não pode se restringir ao atendimento na cadeira do dentista, mas deve estar presente em todos os ambientes intermediários, principalmente no momento da espera pela consulta. 2 M1 conclui em seu relato, envolvendo o lado negativo e/ou dificuldade para o atendimento relacionado ao horário 
noturno do atendimento das crianças: [...] eu moro muito longe, pra sair com duas crianças é perigoso.

\subsection{O DENTISTA IDEAL SOB A ÓTICA DAS MÃES}

Do ponto de vista da caracterização do dentista ideal das mães que participaram desta pesquisa foi valorizada simpatia, capacidade técnica e o vínculo profissional com o paciente (criança). A preocupação materna delas é com a postura mais humana, como fator preponderante do profissional, um tratamento de qualidade e que a criança sinta conforto psicológico durante os procedimentos.

Um bom dentista é aquele que valoriza o relacionamento interpessoal, estabelecendo uma comunicação adequada com o paciente, fornecendo informações relevantes para a manutenção da saúde bucal e dispensando atenção e carinho à criança. $^{3}$ Outros elementos citados pelas mães como importantes relacionam-se às habilidades cognitivas e psicomotoras e, ainda, gostar da profissão e realizar encaminhamento a um profissional especializado, quando necessário. Porém para M1 à afinidade cirurgião-dentista e paciente é de grande valia [...] A simpatia, se tiver a simpatia ela conquista a criança na hora.

De acordo com Almeida et al. ${ }^{2}$ um dentista ideal, na percepção das mães entrevistadas, é aquele que tem atenção com os pacientes - valorizando, assim, a relação interpessoal -, que executa o procedimento de forma correta e que, além disso, educa as mães e as crianças, em cada uma das etapas do atendimento, entrando em concordância com a percepção e fala da M2:[...]Tem que saber o que está fazendo, ser um bom profissional e procurar fazer da melhor maneira possível né?!

Para muitas mães o laço afetivo que o dentista cria com a criança é um ponto chave: [...] A princípio ele(dentista) não deve agradar a mim, que sou mãe, mas sim a criança, o vínculo dele deve ser direto com a criança. (M3).

Contudo na pesquisa de Almeida et al. ${ }^{8}$ a maioria escolheria o dentista devido à experiência, confiaria nele por motivos de resolução do problema, apresentação do consultório, apresentação visual do dentista, característica emocional do profissional, valores estes que não estão relacionados com a interação dentista criança. Para essas pessoas tanto as características profissionais do dentista como as características 
pessoais são relevantes para elas se sentirem confiantes após terem feito a escolha do dentista.

O cirurgião-dentista precisa ser professor, treinador, motivador, psicólogo, educador, possuir capacidade de distrair a criança e ter autoridade ao utilizar as técnicas de linguagem. O domínio linguístico requer ainda que ele seja um comunicador. ${ }^{9}$ Deve-se ter em mente que a proposta de um dentista ideal, seja qual for, talvez seja, em sua totalidade, inalcançável, considerando a condição humana que leva a falhas. ${ }^{2}$

\section{CONSIDERAÇOES FINAIS}

O ponto de vista materno é um importante instrumento, por fornecer informações não só sobre a assistência prestada, mas também sobre a qualidade do ensino na Universidade. Com isso, esta pesquisa possibilitou conhecer a percepção deste grupo de mães e revelou que elas se encontram satisfeitas com o tratamento oferecido na Clínica Escola de Odontopediatria da Universidade de Gurupi, mesmo com os pontos negativos, que foram à demora quanto ao atendimento e a distância da residência para a clínica. Os alunos apresentaram características que os tornaram para estas mães dentistas ideais, pois eles estabeleceram vínculo com a criança, são bons profissionais e trataram bem o paciente.

É de extrema importância ressaltar que os dados da presente pesquisa foram extraídos de uma amostra de mães de crianças atendidas na clínica escola de Odontologia da Universidade de Gurupi. Diante desse fator os resultados não podem ser generalizados, contudo ajuda na compreensão da realidade de como as mães avaliam o atendimento infantil oferecido na Instituição pesquisada.

Deve-se levar em consideração que durante esta pesquisa ocorreu à pandemia da Covid-19 e posterior suspensão de aulas, com isso não foi possível consultar mais mães e obter mais dados para a pesquisa. Porém isso não impede que após a pandemia o estudo seja retomado para maior número de mães entrevistadas e mais resultados.

\section{REFERÉNCIAS}

1.Meira Filho MMO, Araújo DTC, Menezes VA, Garcia AFG. Atendimento odontológico da criança: percepção materna. RGO 2009;57(3):311-315. 
2.Almeida, Tatiana Frederico de et al. Percepções de mães de pacientes sobre o atendimento odontológico na Clínica de odontopediatria da Escola Bahiana de Medicina e Saúde Pública. RFO, Passo Fundo, v. 19, n. 2, p. 172-179, maio/ago. 2014.

3.Robles, Ana Carolina Couto; Grosseman, Suely; Bosco, Vera Lúcia. Satisfação com o atendimento odontológico: estudo qualitativo com mães de crianças atendidas na Universidade Federal de Santa Catarina. Ciência \& Saúde Coletiva, 13(1):43-49, 2008

4.Góes MPS, Domingues MC, Couto GBL, Barreira AK.Ansiedade, medo e sinais vitais dos pacientes infantis. Odontol Clín. 2010;9(1)39-44

5.Albuquerque CM, Depes CVG, Martins Moraes RC, Barros RN, Couto CF. Principais técnicas de controle de comportamento em Odontopediatria. Arq Cent Estud Curso Odontol Univ Fed Minas Gerais. 2010; 46: 110-154.

6. Rigo L, Dalazen J, Garbin RR. Impact of dental orientation given to mothers during pregnancy on oral health of their children. Einstein (São Paulo). 2016;14(2):219-25.

7.Mota LQ, Farias DBLM, Santos TA. Humanização no atendimento odontológico: acolhimento da subjetividade dos pacientes atendidos por alunos de graduação em Odontologia. Arq Odontol. 2012;48(3):151-8

8.Almeida, Flávia Maria de et al. Características relevantes para o estabelecimento de confiança na odontopediatra. Odontol. Clín.-Cient. 2015.4(3) 695 - 698, jul./set., 2015.

9.Leite, Dayane Franco Barros, et al. Condução Psicológica do paciente infantil em Saúde Pública. Odontol. Clín.-Cient.2013. 12 (4) 251-254, out./dez. 